\title{
Mobilizing Intuitive Judgement during Organizational Decision Making \\ When Business Intelligence Is Not the Only Thing That Matters
}

Constantiou, loanna; Shollo, Arisa; Vendelø, Morten Thanning

\author{
Document Version \\ Accepted author manuscript \\ Published in: \\ Decision Support Systems \\ DOI: \\ 10.1016/j.dss.2019.04.004 \\ Publication date: \\ 2019 \\ License \\ CC BY-NC-ND
}

Citation for published version (APA):

Constantiou, I., Shollo, A., \& Vendelø, M. T. (2019). Mobilizing Intuitive Judgement during Organizational Decision Making: When Business Intelligence Is Not the Only Thing That Matters. Decision Support Systems, 121(June), 51-61. https://doi.org/10.1016/j.dss.2019.04.004

Link to publication in CBS Research Portal

\section{General rights}

Copyright and moral rights for the publications made accessible in the public portal are retained by the authors and/or other copyright owners and it is a condition of accessing publications that users recognise and abide by the legal requirements associated with these rights.

\section{Take down policy}

If you believe that this document breaches copyright please contact us (research.lib@cbs.dk) providing details, and we will remove access to the work immediately and investigate your claim. 


\section{Mobilizing Intuitive Judgement during Organizational Decision Making: When Business Intelligence Is Not the Only Thing That Matters}

Ioanna Constantiou, Arisa Shollo, and Morten Thanning Vendelo

Journal article (Accepted manuscript*)

\section{Please cite this article as:}

Constantiou, I., Shollo, A., \& Vendelø, M. T. (2019). Mobilizing Intuitive Judgement during Organizational Decision Mlaking: When Business Intelligence Is Not the Only

Thing That Matters. Decision Support Systems, 121(June), 51-61.

https://doi.org/10.1016/j.dss.2019.04.004

DOl: 10.1016/j.dss.2019.04.004

* This version of the article has been accepted for publication and undergone full peer review but has not been through the copyediting, typesetting, pagination and proofreading process, which may lead to differences between this version and the publisher's final version AKA Version of Record.

Uploaded to CBS Research Portal: March 2020

(C) 2019. This manuscript version is made available under the CC-BY-NC-ND 4.0 license http://creativecommons.org/licenses/by-nc-nd/4.0/ 


\section{Accepted Manuscript}

Mobilizing intuitive judgement during organizational decision making: When business intelligence is not the only thing that matters

Ioanna Constantiou, Arisa Shollo, Morten Thanning Vendelø

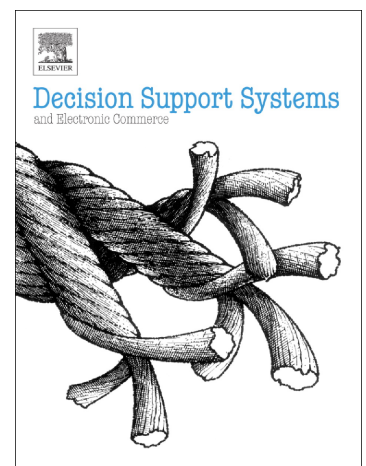

PII: $\quad$ S0167-9236(19)30071-5

DOI: $\quad$ https://doi.org/10.1016/j.dss.2019.04.004

Reference: DECSUP 13055

To appear in: $\quad$ Decision Support Systems

Received date: $\quad 3$ February 2019

Revised date: $\quad 23$ April 2019

Accepted date: $\quad 23$ April 2019

Please cite this article as: I. Constantiou, A. Shollo and M.T. Vendelø, Mobilizing intuitive judgement during organizational decision making: When business intelligence is not the only thing that matters, Decision Support Systems, https://doi.org/10.1016/ j.dss.2019.04.004

This is a PDF file of an unedited manuscript that has been accepted for publication. As a service to our customers we are providing this early version of the manuscript. The manuscript will undergo copyediting, typesetting, and review of the resulting proof before it is published in its final form. Please note that during the production process errors may be discovered which could affect the content, and all legal disclaimers that apply to the journal pertain. 
MOBILIZING INTUITIVE JUDGMENT DURING ORGANIZATIONAL DECISION MAKING:

WHEN BUSINESS INTELLIGENCE IS NOT THE ONLY THING THAT MATTERS

\section{Ioanna Constantiou*}

Department of Digitalization/ Department of Applied IT

Copenhagen Business School, Denmark/ Gothenburg University, Sweden

\section{Arisa Shollo}

Department of Digitalization, Copenhagen Business School

\section{Morten Thanning Vendelø}

Department of Organization, Copenhagen Business School

*Corresponding Author Address:

Ioanna Constantiou

Department of Digitalization

Copenhagen Business School

Howitzvej 60, 4th floor

2000 Frederiksberg, Denmark 


\title{
MOBILIZING INTUITIVE JUDGMENT DURING ORGANIZATIONAL DECISION MAKING: WHEN BUSINESS INTELLIGENCE IS NOT THE ONLY THING THAT MATTERS
}

\begin{abstract}
Academics have argued that data-driven decision processes will replace intuitive judgements, but the empirical aspects of this claim are understudied. We provide empirical findings of how managers communicate and share intuitive judgements when BI system's output is prescribed to be the main information source for decision making. We investigate organizational decision making regarding IT project portfolio investments. We used a rich empirical dataset from a longitudinal, qualitative study investigating the prioritization of IT projects in a large financial institution. Our findings show that decision makers employ four techniques to communicate and share intuitive judgements during organizational decision making, which built on the BI output. Furthermore, we found that the use of these techniques depends on the decision maker's familiarity with the group and the convergence of perceptions about either a project, or specific issues in the group.
\end{abstract}

Keywords: intuitive judgement, organizational decision making, strategic decisions, BI system, project prioritization process 


\section{Introduction}

The tendency of managers to rely on intuitive judgements in decision making is well documented (Hodgkinson et al., 2008, 2009). This tendency is hindered by two organizational features. First, organizations may impede the use of intuition; for example, organizations may prescribe the use of specific tools and analytical processes for decision making (March, 2006). Second, the recent advent of sophisticated information technologies, such as business analytics or business intelligence, promotes analytical processes and the extensive use of data in decision making (McAfee et al., 2012). Although organizations have recently adopted business intelligence (BI) and big data technologies to support data driven and evidence-based decision making processes, researchers argue that intuition remains an important determinant for strategic decisions (Arnott et al. 2017; Kowalczyk and Buxmann, 2015; Shollo et al., 2015; Tingling and Brydon, 2010).

We investigated organizational decision making in an organization using state-of-the-art information technologies, i.e., a BI system to support analytical processes. We focused on prioritization meetings where senior managers make decisions regarding project portfolio investments, which are important as they contribute to the organization's innovation strategy. Empirical studies highlight the importance of such meetings for firm strategy (Ghasemzadeh and Archer, 2000; Tian et al., 2005; Kester et al., 2011). In spite of the mandatory use of a BI system to analyse the decision alternatives, in order to optimize decision making processes, the decision makers appeared to rely on their intuitive judgments in a number of situations. We, therefore, turned to the literature on intuition in organizational decision making to understand how decision makers behave during the decision making process and observe the use of intuitive judgements at the organizational level (Hodgkinson et al., 2009; Salas et al., 2010). In the organizational decision making literature, there are many recent calls for research on the interplay between intuition and analytical thinking. For example, Salas et al. (2010) called for research on how 'people communicate or share their intuitions if they are not immediately defensible in a rational sense' (Salas et al., 2010: 965). Sadler-Smith claimed that research on 'how intuitive expertise is embodied and 
enacted in organizational settings is a rather understudied phenomenon.' (2016, p. 1085) Using our empirical observations and these calls for research as our study foundation, we investigated the following: How do managers communicate and share intuitive judgements during project prioritization meetings in an organization where BI systems are the canonical technologies?

We responded to the recent calls for research by presenting a case that involves an organization in which state-of-the-art IT solutions (i.e., business intelligence systems) are deployed to support decision making and decision makers have long-term experience and in-depth knowledge regarding the domains for which the IT solutions were developed. We observed how decision makers with intuitive expertise (Kahneman and Klein, 2009) communicate and share intuitive judgements during organizational decision making in the prioritization process. We contribute to Arnott et al. (2017) and Kowalczyk and Buxmann (2015) by showing how the interaction between intuitive judgments and the BI system output takes place in practice. We identify and describe four techniques used by a decision maker to communicate and share intuitive judgements in the decision making process. The empirical setting is a financial institution in Northern Europe, and we used a rich dataset from an intensive case study that explored a full cycle of an IT project

prioritization process in this organization. We combined methods, meeting observations and retrospective reports to capture the techniques used by decision makers to communicate and share their intuition during the organizational decision making process.

To achieve this purpose, this paper is structured as follows. First, we present the theoretical background and our research position. Second, we present the research methods. Third, we describe the empirical context. This is followed by an examination of how intuitive judgments are communicated and shared in a project prioritization process and a discussion of our findings and contributions. Finally, we conclude and suggest directions for future research.

\section{Research on intuition and decision making}

The role of intuition in decision making has been investigated by numerous researchers in different fields, who emphasized cognitive or social psychology elements, organizational and managerial aspects and 
strategic implications. The findings are mixed. For example, when focusing on individual information processing under uncertainty, intuition has been associated with cognitive biases (Kahneman, 2003), whereas under conditions of ambiguity, intuition has been found to be beneficial in decision making tasks (Dane and Pratt, 2007).

An early focus on the role of intuition vis-à-vis rationality acknowledges that intuition is an alternative to the rational mode of thinking (Barnard, 1938) and suggests that it contributes to decision making because individuals possess a limited information processing capacity (Simon, 1955; 1987). Cognitive psychologists have associated intuition with heuristics (Kahneman et al., 1982), which serve as shortcuts to reduce the decision maker's cognitive burden in situations of uncertainty. This approach emphasizes cognitive biases due to simplifications or inattention to environmental cues (Payne et al., 1993). Scholars have proposed ways to avoid cognitive biases and develop practices of rational decision making (Bazerman and Moore, 2008). Other researchers have adopted a broader view of intuition rather than viewing it from the perspective of heuristics and have thereby opened several alternative research streams, which are described below.

\subsection{Major research streams of intuition and organizational decision making}

The literature on intuition, which has been developed during the recent decades, offers a variety of definitions that emphasize the following two main characteristics: the holistic association or hunch and the automated, non-conscious reaction due to expertise (for a review see Hodgkinson et al., 2008). Intuition has been investigated in relation to organizational aspects, such as organizational culture, managerial cognition and strategic decision making (for a historical overview see Akinci and SadlerSmith, 2012).

Evidence of the positive influence of intuition on organizational performance can be found in several studies. Ritchie's et al. (2007) study of non-profit organizations showed that efficiency, as described by financial performance measures of expenses and revenues, was positively related to the executives' use of intuition. Similar results highlighting the positive relationship between intuition and financial 
performance (i.e., sales growth) were reported in a study investigating cognitive styles and entrepreneurship in small and medium-sized enterprises (Sadler-Smith, 2004).

The main research streams which provide insights about the interplay of intuition and analytical thinking in the context of organizational decision making are; dual process theories and naturalistic decision making.

Dual process theories. The dual process theories manifest the information processing perspective on intuition and build on cognitive and social psychology (Epstein, 1994; Evans, 2003; Hodgkinson et al., 2008). Stanovich and West (2000) proposed the following two systems of thinking: the intuitive or perceptual 'System 1', and the reason-based 'System 2'. Researchers have investigated the interactions between these two systems, resulting in contradictory conclusions that either System 2 monitors the activities of System 1 (Kahneman, 2003) or that System 1 dominates System 2 (Evans, 2010).

Throughout the years, two different perspectives on the interactions between Type 1 (derived from System 1) and Type 2 (derived from System 2) processes have emerged. The dual process theories are clustered into; default-interventionist theories, which assume that Type 1 processes generate intuitive default responses, on which Type 2 processes may or may not subsequently, intervene (Evans and Stanovich 2013) and parallel competitive theories which assume that Type 1 and Type 2 processes are activated in parallel and when the two responses generated are in conflict, some kind of resolution occurs (Handley et al 2011). Recent research has highlighted the relevance of the parallel competitive theories for organizational decision making, for example, in case of dynamic capabilities (Hodgkinson and Healey (2011, 2014), or team cognition (Healey at al. 2015). Hodgkinson and Sadler-Smith (2018) offered a thorough review of this academic debate and depicted the implications for strategic decision making from re-thoerizing the roles of intuition and analysis based on the parallel comeptitive theories.

Researchers view rational analysis and intuitive judgement as complementary processes in decision making (Hodgkinson and Clarke, 2007). Burke and Miller (1999) proposed that intuition based on experience is used to fill in the blanks when quantitative data is lacking in strategic business decisions and 
that more experienced people use their intuition more. Hough and Ogilvie (2005) suggested that managers who use a combined intuitive-analytical cognitive style can make cognitive leaps and use objective information to reach decisions of higher quality than other managers. Woiceshyn (2009) examined how CEOs combine rational analysis and intuition and found that the two approaches interact constantly in the information management processes used by effective CEOs. Turning to the team composition, Hodgkinson and Clarke (2007) proposed a typology of contrasting cognitive styles that is rooted in the dual process model, and discussed the relationship between the cognitive styles and the composition of groups or teams. These authors suggest that internal conflicts lead to underperformance if a team includes managers with pronounced differences in their cognitive styles, and there is no strong leadership to manage the team. Hodgkinson et al. (2009) argued that a team's composition must include a careful mix of both analytical and intuitive members to enhance its information processing capabilities.

The interplay of intuition and analytical thinkink has also been incorporated in the DSS literature. For example, Kuo (1998) advocated for combining managerial intuition with the analytic capability of the computer for better decisions. Padmanabhan and Tuzhilin (1999) developed algorithmic methods that take into account managerial intuition by eliciting managers' beliefs about the domain and using these beliefs to seed the search for more unexpected insights. In a recent study, Kowalczyk and Buxmann (2015) focused on the analysts perspective and demonstrated that both intuition and rationality are important for the quality of decisions' outcomes. They also argued that a higher rationality-intuition ratio offers the best outcomes.

Naturalistic decision making. This line of research emphasizes the role of experience and expertise in intuition (Crandall et al., 2006; Klein, 1998; 2003; Klein et al., 1993; Sadler-Smith and Sparrow, 2008). This perspective describes how an individual's expertise allows for pattern recognition due to information stored in memory and recognition-primed decisions (Chase and Simon, 1973; Klein, 1998). Intuitive expertise is developed subconsciously before a manager consciously detects the behavioural patterns of information acquisition and uses this expertise in corresponding tasks (Lewicki et al., 1992). Intuitive 
expertise has been investigated in specific professions, such as chess players, firefighters, surgeons, and military personnel (see Kahneman and Klein, 2009; Klein, 1998, 2003).

Expertise has been considered a precondition for, or antecedent of, successful intuitive judgement (Dane and Pratt, 2009; Hodgkinson et al., 2009). For example, Khatri and $\mathrm{Ng}$ (2000) claimed that intuition could be effective when it derives from years of experience in problem solving and is founded on a solid and complete grasp of the details of the business. Sadler-Smith and Shefy (2004) investigated intuition as a feeling and an expertise, and found that intuition is strongly present in organizations, particularly at the executive level. Additionally, these authors suggested that there is a positive correlation between intuitive expertise and management seniority due to holistic and visionary thinking, hierarchical positioning and the importance of soft data in decision making. Miller and Ireland (2005) claimed that intuition, either as a holistic hunch or an automated expertise, can be troublesome for organizations with either an exploitation or exploration focus. However, in the case of exploration, intuition in the form of holistic hunches enables the organization to move away from existing practices and, thus, explore new technologies or strategies through experimentation and other more risk-taking activities.

Our review of the literature on the interplay of intuition and analytical thinking in organizational decision making has shown that despite the numerous thorough conceptual analyses of intuition and studies of intuition in specific organizational contexts, there is scarce empirical evidence regarding how intuitive judgements are communicated and shared in the decision making process.

Intuition is an individual phenomenon, and its expression through intuitive judgements should be captured in a systematic way before we are able to observe how it is communicated and shared in organizational decision making. As the foundation of our study, we considered experience and expertise as antecedents of intuition (Dane and Pratt, 2009; Sadler-Smith, 2016) and focused on senior managers with intuitive expertise (Kahneman and Klein, 2009). We adopted the three-phased intuit-intuitionimplementing model' developed by Sadler-Smith (2016), which is based on a field study and represents a first attempt to understand how intuitive expertise is embodied and enacted in organizations where analytical tools are prescribed for decision making. In this model, the individual 'intuits', which is a phase 
of rapid, subconscious, automatic information processing, and then, intuition emerges as a bodily and/or cognitive awareness about a specific choice; finally, the intuitive judgement, such as a behavioural response to signals or information, is acted upon by anticipating, judging, questioning or deciding. Our empirical data allow us to observe the second and third phases of the model, while the data provide indications regarding the first phase. In particular, we used interview data to identify intuition in our participants' descriptions of the decision making process during a project prioritization and how decision makers act upon their intuitive judgements. Building on this model, we investigated how decision makers communicate and share their intuitive judgments in a data-driven decision making process where the BI systems are the prescribed information sources for project prioritization.

\section{Research Method}

This study draws on data from an eight month study of an annual project prioritization processes in the IT unit at a large bank in Northern Europe (see the online data supplement for more information on the research setting). The annual project prioritization process is concluded with a number of project prioritization meetings, in which the participants (decision makers) prioritize IT projects. We use these meetings as examples of organizational decision making, and undertook an in-depth study (Yin, 2003), in order to explore the communication and sharing of intuitive judgements during these meetings, where the BI systems are the prescribed information sources.

\subsection{Data collection}

We collected data about the organizational context and documented the project prioritization process. Although the company headquarters resided in a non-English speaking country, its formal language (spoken and written) was English. Several data collection techniques were applied; real-time observations, recordings of meetings, semi-structured interviews, and collection of documents produced by the organization. The real-time observations in two subunits of the IT unit allowed us to establish an understanding of the daily activities and the context of the project prioritization process. We collected 
data for two weeks with one author observing the managers in their natural setting. The resulting field notes (35 pages) were used as background information in the analysis.

The core body of the empirical data includes eight recorded project prioritization meetings, which were transcribed verbatim resulting in a total of 170 pages and 43 semi-structured interviews with managers (see Table 1). Data were transcribed verbatim (totalling 730 pages). We followed an evolutionary, iterative approach in which the data collection techniques supported each other. For example, meeting observations were used as inputs to follow-up interviews.

From April to June 2010 we conducted 30 semi-structured interviews with decision makers participating in project prioritization meetings, and thereby, we collected the decision makers' personal views of the prioritization process. In particular, we interviewed 19 informants from the IT unit, who had different levels of seniority, and 11 informants from the business units. We used a semi-structured interview guide and open-ended questions about the prioritization process. Each interview lasted, on average, 50 minutes.

\begin{tabular}{|c|c|c|}
\hline & IT unit & Business units \\
\hline $\begin{array}{l}\text { First round of } \\
\text { interviews }\end{array}$ & $\begin{array}{l}1 \text { Corporate level Officer } \\
7 \text { IT Development Directors } \\
3 \text { IT Development Managers } \\
5 \text { IT Analysts } \\
3 \text { Portfolio Managers }\end{array}$ & $\begin{array}{l}3 \text { Senior Business Representatives } \\
7 \text { Junior Business Representatives } \\
1 \text { Business Analyst }\end{array}$ \\
\hline $\begin{array}{l}\text { Second round - } \\
\text { follow-up interviews }\end{array}$ & $\begin{array}{l}2 \text { IT Development Directors } \\
2 \text { Portfolio Managers } \\
4 \text { IT Development Managers }\end{array}$ & $\begin{array}{l}2 \text { Corporate level Officers } \\
1 \text { Executive Member } \\
2 \text { Senior Business Representatives }\end{array}$ \\
\hline
\end{tabular}

\section{Table 1: Information about the interviewees}

We observed eight project prioritization meetings (from June to October 2010). We followed two subunits of the IT unit and participated in the third and fourth quarter (Q3 and Q4) prioritization meetings 
of the corresponding Prioritization Groups (PGs). We focused on the Q3 and Q4 meetings, as during these last meetings the final priorities were assigned to the proposed projects.

We conducted thirteen semi-structured follow-up interviews to these meetings (from October 2010 to April 2011). These interviews focused on specific events during the meetings, such as projects discussed or decisions made. In these interviews, the authors elaborated on the discussions, arguments and decisions made during the observed meetings.

Finally, we gathered additional background material, such as presentations, meeting minutes, reports, organizational charts and memos (see Figure 1). We studied these documents to gain further insights into the prioritization process and triangulate the data sources with the interviews and the meeting observations (Lee, 1999).

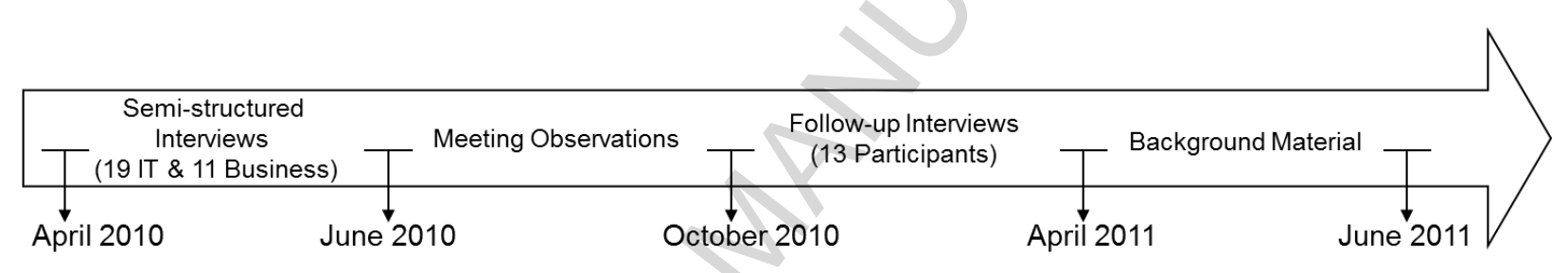

\section{Figure 1: The data collection process}

\subsection{Data analysis}

We employed constant comparative techniques (Strauss and Corbin, 2008) to analyse the data in a systematic and iterative manner. First, we read the interviews and meetings' transcripts as well as the background material and field notes, and thereby, we developed a detailed overview of the empirical setting, as well as of the project prioritization process. Second, we went through all the documents and meeting transcripts to identify the common components in the raw data across the different sources. Based on the in-vivo coding technique (Strauss and Corbin, 2008) we then organized these first-order codes into tables, which support every single theme included in the data-structure (Figure 2). Third, we determined the second-order themes by focusing on how managers communicated and shared their intuition during prioritization processes. Once we sorted the raw data, we further analysed the data to identify higher-order themes by searching for patterns and overlaps among the second-order categories 
using the so-called axial coding technique (Strauss and Corbin, 2008). This analysis was conducted in several iterations until the authors agreed on the final themes and could find no further overlaps among the themes. Finally, through an iterative analysis, 'presenting intuitive judgement', 'framing calculations', 'appealing to an expert' and 'connecting to the group context' emerged as the core observable phenomena in the data (Eisenhardt, 1989). Hence, the analysis evolved in an iterative process in which the data were compared with emerging themes in a cyclical manner inspired by Miles and Huberman (1994).

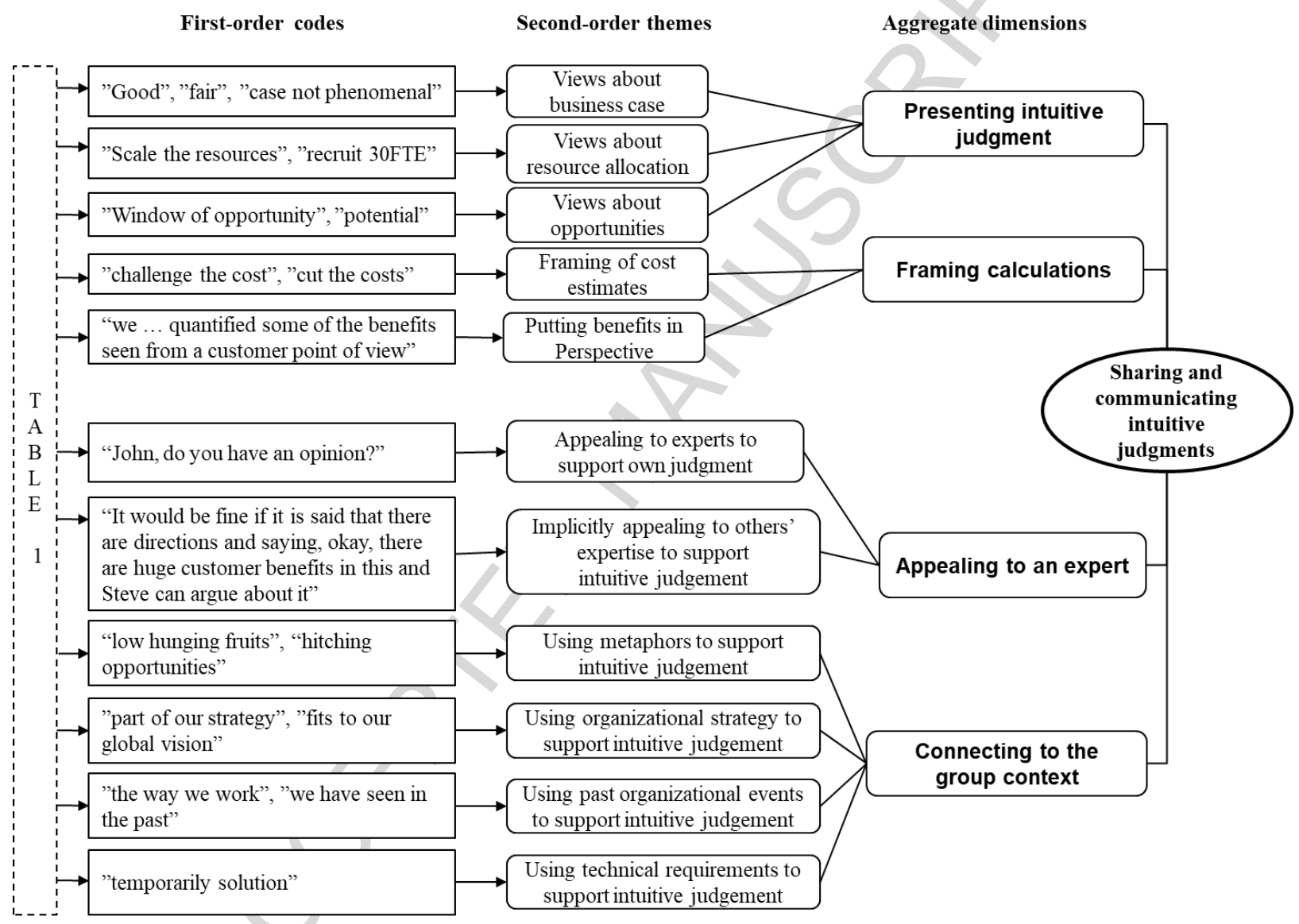

Figure 2: Data structure: From first-order codes to aggregate dimensions

Inspired by Rosemann and Vessey's (2008) applicability check method we conducted two workshops with the study participants. During the workshops, we presented the findings and then discussed them with the study participants by asking questions to elicit their views, comments and reactions. The discussions revolved around the validity of the findings, and the participants largely confirming the 
results. In particular, the head of the IT Governance stated the following: 'We are not surprised. The picture that you are painting feels right' (Notes from workshop). The workshops, thus, served as a validation of our findings.

\section{Empirical context of the project prioritization}

We depict the main activities of the decision makers before the prioritization meeting and then describe the BI output used in the process. Finally, we present how a typical meeting unfolds.

\subsection{Activities before the project prioritization meetings}

The development of a project idea is a bottom-up process initiated by either a business or IT unit manager. The idea evolves through debates among the development managers, business representatives, IT project managers and IT developers. When the project idea is sufficiently mature, a manager prepares a memo that includes a brief description, an initial cost-benefit analysis, and a brief description of the expected benefits.

A development manager then develops the memo into a project proposal that is supplemented by IT developers' cost estimates and assessment of the technical feasibility. The initial project proposal is reviewed internally before the development manager presents the proposal to the PG. The development manager also searches for additional supporters/sponsors in the organization to increase the chances of the project proposal being included in the prioritization list.

The development manager and other business representatives, who are the decision makers in the PG, hold an informal meeting about the project proposals and form their opinions. They also exchange information about the availability of resources in the coming year. Regarding the selection of projects, intuition as bodily awareness, is described by decision makers as follows: 'at the end of the day, [we] 
look at [the projects] and ask "what is my feeling ... about this ... project?"' (Senior Business Representative).

Decision makers also expressed cognitive awareness as follows: 'We are not making any money on [application X], but on the other hand, we have had the best publicity in the last three years. Therefore, this is not looking very attractive from an IT investment point of view, but if this can turn the total look of the company around, then it is probably the best investment we have ever made' (Senior Business Representative).

\subsection{The BI output}

The BI output in IT project prioritization is the outcome of a cost-benefit analysis. The project manager or idea owner makes cost calculation. For new projects, data for the cost calculations are gathered from the HR management information system (MIS) and from the enterprise finance system before they are further analyzed in the spreadsheet-based BI application. For ongoing projects, cost data are gathered from the project administration manager, a BI system for monitoring the progress of projects under development. Data for the benefit calculations are gathered from many different systems. If the benefits are related to the branch network then the Group Management Information (GMI) system, a business intelligence system primarily targeted for the branch network to enable them to make decisions locally in the market, is used. If the benefits concern sales then the data are gathered from transaction systems such as the loan, accounts and cards systems. When the benefits concern intangible benefits there are very few data sources available. Customer satisfaction data are available through the GMI system, while data on customer experience are collected from the e-banking platform where users' activity is tracked. Data about intangible benefits such as a better image of the bank or future sales are ultimately not available from any system, and are based on estimates. Once the costs and benefits of a project are identified and extracted from the different BI systems, they are sourced into a spreadsheet-based BI application where the costbenefit ratio for the project is calculated, as well as the Net Present Value for two and five years. In the following section, we describe how a project prioritization meeting unfolds.

\subsection{Project prioritization meeting}


Typically, 10 to 12 decision makers participate in a prioritization meeting. These involve; a development manager (who serves as the secretary), development directors of the PG's departments, other development directors in related areas, business representatives, IT personnel specializing in relevant domains, the $\mathrm{CIO}$, and the $\mathrm{COO}$ (Chief Operation Officer). The group members have been working together for at least three years and have, on average, 10 years of experience in the organization.

The PG secretary prepares the meeting agenda and presents a preliminary prioritization list. The presentation includes the following: a) ongoing projects, b) compliance projects and c) new projects. There are more new projects than the PG can initiate with its budget; thus, resources will be allocated to the project that is highest on the prioritization list. The projects appear on a spreadsheet with standard information from the BI system regarding the net present value, cost estimations, full-time employees (FTE), benefits, time schedule, sub-deliveries, and releases. Each new project is presented in the meeting. The PG members discuss the facts and ask about the business rationale (e.g., cost savings compared to other project proposals in the list). The discussion continues until the PG members agree on the priority of each project in the list.

During the interviews, the decision makers reflected on the decision making process during the meetings. Intuition as a bodily awareness was repeatedly described as 'people that really convince me make me also feel in my gut that they know what this means if we go out and try to implement [it]' (Senior Business Representative).

Intuition as a cognitive awareness was also expressed as follows: 'senior executives can choose to disregard all the financial data; if they feel this is important, they will ask us to do it no matter what'. Mental images were mentioned explicitly as follows: 'they had a mental image of what they thought it would cost'.

Decision makers respond to their intuitive judgements by anticipating other people's responses as follows: 'I had a feeling that they thought it was a bit too expensive. We had calculated the total cost of ownership over five years, and the cost is set to five million; so, we are going to remove everything that's 
administration of the system after implementing; then, I'm down to two [million]' (IT business developer).

Decision makers decide on projects based on their intuitive judgements as follows: 'The pilot test had at worst been inconclusive, and the feedback from everyone had been... well, maybe we shouldn't do it; my gut feeling tells me’. (Business Representative).

In other situations, intuitive judgements evoke more questions as follows: 'They said to me, "well, it works that way", but you've got a feeling it doesn't make sense. Why would people make it that way? And then, you try to pursue it a little more' (Business Director).

\subsection{Activities after the project prioritization meetings}

The prioritization list decided in the meeting is then forwarded to a portfolio management office that collects, consolidates, and analyzes the prioritization lists received from the different PGs. A draft portfolio of IT projects is submitted to the IT executive committee that meet to make the final approval. The chairman of each PG presents the prioritization list to the committee and provides information on each project, including its name, scope, net two- and five-year present value, total costs and benefits, priority number on the list, and strategic focus area. The IT committee then decides the overall portfolio of IT projects for the coming year. The IT committee may move project proposals up or down on the prioritization list and exercises some discretion in placing the budgetary cut-off line. However, the total budget and its distribution across departments does not change radically in the process.

\section{Findings on communication and sharing of intuitive judgements}

We identified a total of 56 instances of project prioritization during the eight observed PG meetings; of these instances, 23 involved communication and sharing of intuitive judgements. We next illustrate the four techniques decision makers use to communicate and share intuitive judgements during project prioritization, using representative quotes and dialogues from the eight meetings.

\subsection{Presenting intuitive judgements}


During the meetings, the decision makers explicitly presented intuitive judgements. This technique is manifested in various ways including views about business cases, prioritizations and opportunities.

Decision makers presented their views about the projects' business cases using words, such as: 'attractive cost-benefit case', and 'solid business cases'. For example, in a PG meeting, when a project with a weak business case was discussed, we observed how the different decision makers presented their views. First, a Business Director expressed his intuitive judgement by highlighting the following concerns about the project's prioritization:

'From my perspective, this is not necessarily the best business case I have ever seen', and then, a Development Director presented a similar judgement, making a holistic association as follows: 'it might be worthwhile considering postponing this... in digital banking [a program], we have very good projects that we could get in the Development Center in India, and it might be a tradeoff then' (meeting 1.2, project 17).

Decision makers also presented intuitive judgements about the prioritizations of projects and the use of resources using phrases, such as 'in my opinion, we should try to scale the resources', and 'I would really have preferred to have the resources on this instead'. For example, after discussing the overall resource allocation for the department, a Senior Business Director called attention to the prioritization of a project with a prolonged timeline and raised the issue of resources as follows:

'I'm not happy with the e-registration in Norway and the timeline on that. [The CIO] tells me that we don't like projects more than a year long, and right now, I guess this is one and a half; so, in my opinion, we should try to scale the resources for that in order to actually have it into 2011' (meeting 1.2, project 17).

The Development Director, who was in charge of the programme to which this project belonged, joined the conversation and re-assured the Business Director that they would work more on the issue.

Finally, decision makers expressed their views on opportunities, i.e., cost savings or benefit generation, using wordings, such as 'window of opportunity' and 'gold opportunity'. When presenting the project list, the PG secretary indicated that there were more projects on the list than the department could perform and 
drew their attention to the prioritized project. The PG secretary highlighted the project fit with the current competences to emphasize the pressing opportunity as follows:

'We will really, really love to have [project] DC on our plan because we really need it, and it's now that we have the competences ourselves and also in [the business area] to do this project' (meeting 1.2, project 17).

A Development Director made a holistic association, agreed with the PG's judgement, and proposed to swap the priorities of two projects on the list, assigning a lower priority to another project and prioritizing the project under discussion higher on the list as follows:

'If we should convert DC, it's now! We can always optimize the back office another time, but we only have the limited window of time of when we can actually do this conversion. ...[...] ... I just think we should do it now because it's the best for the group and the customers.' (Meeting 1.2, project 17).

This technique describes how decision makers communicate their intuitive judgement in different occasions in which the BI system's outputs such as the cost and benefit estimations, or other quantitative information about a project, were viewed as an inaccurate representation of the project's value. Decision makers' intuitive judgements are at odds with the project's measures as calculated by the BI system, and they inform the group to change, or reconsider the decision about a project.

\subsection{Framing calculations}

Decision makers framed calculations in alternative ways to the ones presented and thereby, established more convincing arguments for the priority assigned to a project. This technique was manifested by framing cost estimates and placing benefits into perspective.

This technique was observed in the form of framing cost estimations from the BI system to reduce the projected costs. For example, during a meeting, a Business Representative expressed a concern about the timeline of a project, which involved more time than expected, thereby increasing the project cost. The Development Director argued that they were aware of the high costs and would try to re-calculate as follows: 
'But, we are trying to challenge the cost of it, that's basically what we are trying to challenge; so, that doesn't [cost as much]. We know it's high already' (meeting 2.2, project 20).

In another instance, the PG secretary discussed the cost of a project that would allow employees to experience less downtime of the servers and perform their work without interruptions. A Business Representative expressed concerns about the costs and challenged whether this project reflected what the employees experienced in their daily work as follows:

'When we ask our advisors, this is not the picture they are saying at all. [...] I think we have a task where we have to examine, well, what they are talking about. Is this the same thing that we are talking about?' (meeting 2.2, project 24).

The PG secretary agreed and explained how they framed and calculated the costs as follows: 'No, this is actually the server uptime. It's not an end-to-end measurement, no' (meeting 2.2, project 24).

The senior business representative recommended a further examination of the costs to frame the costs as an end-to-end measure that would capture the total impact of the server downtime as follows: 'So actually, you have more issues than this. The total uptime is actually less than this, but this is what we can calculate from IBM' (meeting 2.2, project 24). The PG secretary agreed as follows: 'That is correct. The experienced uptime could be very different from what you see up here' (meeting 2.2, project 24). Finally, the senior Business Representative suggested framing the cost estimates differently as follows:

'I think that you need to dig a little deeper for the other problems that we are talking about, and at least for now, we need to keep this at the level that we have before because right now, it's not good enough at least' (Meeting 2.2, project 24).

Occasionally, decision makers placed in perspective different types of benefits calculated by the BI system (i.e., tangible versus intangible and 'hard' versus 'soft') and the time-horizon for the realization of the benefits (i.e., two versus five years). For example, in one meeting, after the PG secretary's presentation of the prioritized list, a Development Director challenged the prioritization of a project because of its limited benefits and wondered if other projects had more immediate benefits. The PG 
secretary reacted to this challenge by sharing the intuitive judgement of the need for including intangible benefits as a part of the calculated benefits as follows:

'We think that it is an adequate business case, and we would like to challenge ourselves in terms of customer experience. We think that we need to take that into account that's as good as the other types of benefits, and we would actually quantify some of the benefits seen from a customer point of view, and we really think that these also are valid as arguments for the project' (meeting

\section{1 , project 12).}

In the same instance, the CIO placed the benefits into a broader perspective and proposed to add the benefits of future projects that would only be possible because of the project in question as follows:

'Maybe the right thing would be to show the benefit of the first step, but also perhaps to indicate the full potential ... because the full potential is much bigger ... I think when we see the full [potential] ... I have the feeling that it's right, but you have to have the [whole] picture' (meeting

\section{1 , project 12).}

This technique of sharing an intuitive judgement was used by decision makers when they perceived the cost or benefit estimations of the BI system to be poor representations of the actual measures. The decision makers shared their intuitive judgement with the rest of the group to activate their involvement in strengthening the arguments to justify the priority given to a project.

\subsection{Appealing to an expert(s)}

Decision makers occasionally appealed to an expert or experts to validate their intuitive judgements. This technique appeared in two different versions as follows: appealing to experts to support their own judgement and implicitly appealing to others' expertise to support the intuitive judgement.

During a meeting, a decision maker called for or referred to the view of another decision maker with expertise or insights regarding the matter discussed to show that others supported the intuitive judgement. For example, while considering the prioritization of a project, which was questioned by a Development Director due to its limited expected benefits, the PG secretary appealed to an expert, another Development Director with extensive knowledge about the domain of the project, to obtain support for 
the intuitive judgement of the intangible benefits that the project would generate. The PG secretary asked the Development Director's view as follows: 'That's right. John, do you have an opinion [on the matter]?' (meeting 1.1, project 12). The Development Director presented the intuitive judgement as follows:

I agree on the project. Also, the scope, because if you look into my business, we have several different services within this area, and I must say that the number of project steps where we aim is large; so, it's a very complex area, and you can try to solve it all in one project; it will probably never end. So, I must say that although it could seem as the benefit is small, this is putting out a foundation for future work' (meeting 1.1, project 12).

The Development Director responded to the PG secretary's appeal with a supportive intuitive judgement, making a holistic association between the project's importance and future projects.

In another instance, a Development Director spoke about a window of opportunity when discussing the priority of a project. The CIO asked to the Development Director to elaborate. The Development Director, using expert knowledge, explained the challenges and highlighted the urgency of the situation without making suggestions about the project but implicitly appealing for the support of others to the intuitive judgement as follows:

'Those people who can actually do this [project], they will retire within the next couple of years, and then, there would be a much different business case to do the project. It might not even payoff' (meeting 1.2, project 17).

This statement urged another Development Director to support the intuitive judgement presented.

'The down side is that it will cost more resources at the end of the day to do the same exercise [if we don't do it now]' (meeting 1.2, project 17).

The PG secretary, who knew the competences needed for the project, offered additional support as follows: 
'The thing here is that the more resources are retired, the harder it is to make the changes; every time, we always maintain 2 systems as it is. That means customer experience will definitely decrease. Right? because they won't experience the same' (meeting 1.2, project 17).

This technique of sharing intuitive judgement was used by decision makers when they needed additional support to convince other decision makers in the group who held opposing views. Enrolling another expert opinion could be explicit by directly calling upon a group member or implicit without suggesting a decision but expressing a view based on personal experience.

\subsection{Connecting to the group context}

Decision makers shared intuitive judgements by connecting the judgements to issues that were commonly accepted in the PG, and thereby, the decision makers connected the judgements to the group context. This technique was manifested in various ways, such as the use of metaphors, reference to organizational strategy, past organizational events and technical requirements.

During the meetings, the decision makers used metaphors to support intuitive judgments. For example, a Business Representative referred to the type of benefits the projects could provide by noting the following: 'I would say we should go for the low hanging fruit' (meeting 1.1, project 10). In another instance, the PG secretary attempted to build a shared understanding of benefits from a specific project as follows: 'The benefit that we have seen is solely from hitching opportunities' (meeting 2.2, project 38).

The organization's strategy was often referenced by the decision makers when they communicated intuitive judgements. In one meeting, the PG secretary presented two related project proposals of which one was the continuation of the other. The PG secretary expressed a positive intuitive judgement by calling them 'solid', 'clear' and 'good' and continued by connecting the intuitive judgement to the global vision of the company and the strategic initiatives. Therefore, the PG secretary could create an understanding of the importance of these proposals and how they fitted into the big picture as follows:

'We think that both proposals are quite clear and quite good, ... and it [they] fits very well to our digitalization initiatives' (meeting 1.1, project 13). 
Decision makers also connected their intuitive judgements to past organizational events. This association facilitated the emergence of a shared understanding because most of the other decision makers were familiar with these events, and thus, they could easily relate to them. For example, in a meeting, the decision makers were introduced to a proposal for a project converting an IT system from an old platform to a new platform. According to the proposal and the estimated time, it would take two years to complete the conversion. A Development Director challenged the proposed solution and suggested that if performed manually, the conversion would take less time.

'We would consider [making] a manual conversion instead of fixing the problems in the systems and do a manual conversion of the data because that's much cheaper' (meeting 1.1, project 7).

The Business Representative involved in the development of the project proposal then stated that they would do an additional iteration of the proposal.

'We would like to do another revision on this[project proposal], taking into account that this mapping exercise might not be that difficult ... therefore, I think the whole project would be more easily defined and more easily going forward than is actually reflected in this note' (meeting 1.1, project 7).

The Development Director responded by referring to a previous similar task to justify the negative intuitive judgement about the current timing of the proposed project.

'One could at least say that if it takes one year to convert a bank [referring to a recent acquisition in another country], it is strange that it takes two years to convert a system' (meeting 1.1 , project 7).

Finally, decision makers referred to technical requirements to mobilize support for their intuitive judgements. By highlighting technical requirements, decision makers enabled the shared understanding of the importance of a project to emerge. For example, when discussing two project proposals presented by the PG secretary as solid business cases, a Development Director mentioned a technical service that the company wanted to develop further to denote the importance of the proposed projects as follows: 
'I really think that these are also projects that we need to do in order to increase the self-service ability. [...] If we don't do that, customers are not going to be able to get into this space. They will not understand what we are saying; so, it's maybe narrow to look at it just from a back-office perspective. I really think that we need to clean it up in order to make it friendlier to the customers' (Meeting 1.1, project 13).

This technique of communicating intuitive judgement was used when a decision maker had an opportunity to relate the judgement to information, knowledge, or ongoing discussions about specific issues shared by the group. The technique facilitates the convergence of the other decision makers' views towards the intuitive judgement about a project.

\section{Discussion}

Our findings show how an intuitive judgement is communicated and shared during the organizational decision making process in an organization in which established technologies of rationality (March, 2006) such as BI systems are prescribed for project prioritization. Senior managers are prone to use intuitive judgements when these are at odds with quantitative information from the BI system, such as cost and benefit calculations (e.g., Keltner et al., 2003; Miller and Ireland, 2005), during the decision making process. Our study advances research efforts on organizational decision making by showing how an intuitive judgement, which is an individually experienced bodily and/or cognitive awareness (SadlerSmith, 2016), is communicated and shared in data driven processes where decision makers are expected to use the output of BI system to when making decisions. We identified four techniques used by decision makers and observed specific conditions that enable the use of each technique in different contexts. In the following section, we elaborate upon and discuss these contributions to the field.

\subsection{Sharing and communicating intuitive judgements during organizational decision making}

In table 2, we present an overview of the four techniques used by managers to communicate or share their intuitive judgements. These techniques appeal to individual beliefs, attitudes, knowledge experience, or shared mental models (Healey et al., 2015; Salas et al., 2010).

Table 2. Techniques of communicating and sharing intuitive judgements. 


\begin{tabular}{|l|l|}
\hline Technique & Description \\
\hline Presenting intuitive judgement & Explicitly expressing intuitive judgement based on expertise \\
\hline Framing calculations & Providing alternative frames of calculations \\
\hline Appealing to an expert & Enrolling an expert to validate an intuitive judgement \\
\hline Connecting to group context & Relating an intuitive judgement to issues commonly accepted by the \\
& group \\
\hline
\end{tabular}

Presenting intuitive judgements. This technique is used when the decision maker's intuitive judgement is at odds with the prescribed criteria for the project prioritization based on the BI system output. The decision maker may judge the quantitative information about a project as inaccurate and the project's value differently due to intuitive expertise. This technique is similar to expertise-based intuition as discussed in the literature (e.g., Kahneman and Klein, 2009; Klein, 2003). This technique is an example of communication of intuitive judgement in which the decision maker attempts to convince the group by simply presenting the intuitive judgement.

Framing calculations. This technique is used when the decision maker's intuitive judgement is aligned with the prescribed criteria, but the quantitative information provided by the BI system is viewed as weak. The decision maker then shares the intuitive judgement with the group to activate them in strengthening the quantitative information in support of a project decision. The technique is similar to Tingling and Brydon's (2010) 'decision-based evidence making' in which managers provide evidence that agrees with their intuitive judgement to their supervisors or leaders. This technique is an example of sharing the intuitive judgement and co-producing an alternative framing of the outcome with the group.

Appealing to an expert. This technique is used when the decision maker needs to collect additional support to validate an intuitive judgement when other decision makers in the group have aired opposing views on the BI system's output. This technique is similar to the use of experts for support as information sources and influencers (Howell and Higgins, 1990; Markham, 1998) during decision making. This 
technique is an example of sharing the intuitive judgement by explicitly or implicitly seeking an expert's support during the meeting. Experts provide support for intuitive judgements through their knowledge on the topic or simply due to their authority in the group.

Connecting to the group context. This technique is used by the decision maker to communicate the intuitive judgement when there are similar opinions in the group about aspects related to the project. The decision maker presents the judgement by relating it to issues that are commonly accepted by the group and thereby relating it to the group context (Shariq and Vendelø, 2011). This connection occurs when a decision maker has an opportunity to introduce the intuitive judgement due to shared mental models in the group. Several researchers (e.g., Healey et al., 2015; Salas et al., 2010) have emphasized the importance of shared mental models in a group. This technique is an example of communication of intuitive judgement aimed at connecting it to the group context.

It is worth examining the conditions in which each of the four techniques is applied. The two techniques of appealing to an expert and connecting to the group context can be applied solely by a decision maker who is familiar with the group with which the intuitive judgement is shared. Otherwise, the decision maker will not know which expert to appeal to and what context to connect to. Such familiarity with the group is not a prerequisite for applying the two other techniques of presenting intuitive judgement and framing calculations because the application of these techniques relies on the ability to either form an intuitive judgement or develop an alternative frame of the presented calculation, which can be presented to the group. Therefore, the decision maker's use of a technique depends on the level of familiarity with the group. Familiarity is related to shared cognition (Cannon-Bowers and Salas, 2001), and in particular knowledge about others in the group as well as shared attitudes or beliefs among group members.

The two techniques of framing calculations and connecting to the group context can be applied when an in-group convergence exists, albeit in different forms. For example, the technique of framing calculations is mainly effective when the group members' judgements, to a large extent, already converged about a specific project, but additional arguments are needed to support the decision. Similarly, an attempt to connect to the group context is only effective when an in-group convergence exists about the specific 
issue to which an individual relates her or his intuitive judgement. In contrast, the two other techniques of presenting intuitive judgement and appealing to an expert typically occur in situations with a low in-group convergence, as means of convincing other members with different views. Therefore, the decision maker's use of a technique is influenced by the level of in-group convergence. In-group convergence is observed when there are shared mental models about a task and the team, or similar reflective representations (Healey et al., 2015). High in-group convergence corresponds to full cognitive concordance, i.e., high similarity of both reflective and reflexive representations, or mental models (Healey et al., 2015) while low in-group convergence implies illusory cognitive concordance in the group, where there is low similarity of the reflexive mental models but high similarity of the reflective mental models (Healey et al., 2015).

When combining the two dimensions of familiarity with the group and in-group convergence, it is possible to organize the four techniques as shown in Table 3. Thereby, we can show that the techniques available to an individual depend on; a) how familiar that individual is with the group, indicating that a newcomer to the group will find it difficult to either appeal to an expert or relate to the group context, and b) how much group members' attitudes and perceptions converge about either a project or about specific issues.

Table 3. Conditions for communication and sharing of intuitive judgements

\begin{tabular}{|l|l|l|l|}
\hline \multicolumn{2}{|c|}{} & \multicolumn{2}{|c|}{ Familiarity with the Group } \\
\cline { 3 - 4 } & Low & High \\
\hline \multirow{2}{*}{$\begin{array}{l}\text { In-group } \\
\text { Convergence }\end{array}$} & Low & Presenting intuitive judgement & Appealing to an expert \\
\cline { 2 - 4 } & High & Framing calculations & Connecting to the group context \\
\hline
\end{tabular}

\subsection{Contribution and implications}

Our findings contribute to research regarding the role of intuitive judgement in the presence of prescribed data-driven decision tools, i.e., BI system, during organizational decision making. Responding to calls for more empirical studies on the interaction of intuitive judgments and BI at the organizational level (Arnott 
et al, 2017; Trieu 2017; Kowalczyk and Buxmann, 2015), we observed how decision makers introduced intuitive judgements while using the BI output. Kowalczyk and Buxmann (2015) acknowledged the importance of communication tactics used by analysts to signal and convey analytical insights to decision makers. We identified four techniques of communicating and sharing intuitive judgements in organizational decision making. The use of these techniques depends on the manager's familiarity with the group involved in the decision making process and the in-group convergence regarding projects or issues in the organization.

Our findings respond to the calls for empirical studies (Hodgkinson and Sadler-Smith, 2011; SadlerSmith, 2016; Salas et al., 2010) of intuitive judgements at the organizational level. We investigated how managers communicate and share intuitive judgements in organizational decision making in the form of IT project prioritization. We observed experts who judged project characteristics in a different manner than the cost-benefit estimates of the BI system's outcome. We contribute to the discussion about parallel competitive dual process theories and the interplay of Type 1 and Type 2 processes at a group level (Hodgkinson and Sadler-Smith 2018). We argue that managers use four techniques to articulate the intuitive judgements, building on an interplay of Type 1 and Type 2 and convince the other group members who have reached their own judgment following a similar decision processes.

Recently, Healey et al. (2015) proposed two types of shared mental models in groups that affect coordination and performance, thereby emphasizing the importance of further research in this underinvestigated area. We examined decision making in groups where the reflective mental models, deriving from Type 2 processes, are similar. We proposed two conditions influencing the decision maker use of a technique of communicating and sharing intuitive judgments. First, familiarity with the group, which involves knowing the similarity of reflexive mental models in the group and choosing a technique accordingly. Second, in-group convergence, which puts forward the level of similarity of the reflexive mental models and, thus, influences which technique is used. These conditions influence the decision maker choice regarding which technique to use to communicate or share intuitive judgements. Our study provides empirical evidence of how the intuitive judgement of an expert is introduced to the group when 
different types of shared mental models may suggest a different response. Therefore, we provide empirical evidence for the use of intuitive judgement at the organizational level.

The findings of this study have important managerial implications. Given the complex and unstructured problems faced by many organizations, intuitive judgement is an unavoidable property of organizational decision making, making up for the shortcomings of analytical tools such as BI. Managers used the output of BI systems during the project prioritization meeting. However, on several occasions they had to supplement or interpret this output with intuitive judgement, which they then communicated or shared with the group. The four techniques used by managers to communicate and share intuitive judgements during decision making identified in this study are likely to be common to decision making in other organizational contexts. We claim that the conditions in which these techniques are used are also similar in different organizations. Organizations should be aware of our findings when designing and institutionalizing rational technologies to support analytical decision making.

Given the insights generated from our study, it is relevant to consider if an expanded BI system could better support the project prioritization meetings. There are two conditions to be noted. First, given that the BI system provides relevant output to the decision makers for the majority of the decisions, the added features will solely address a small set of decisions. One should thus, assess whether the costs of adding extra features to the BI system can be financially justifiable. Second, given that the intuitive judgments used as input to the decision processes are grounded in contextualized knowledge held and occasionally activated by specific decision makers, it is complicated to anticipate what contextualized knowledge should be included, and for which projects it will be relevant. Hence, the information gathering and processing needed to support specific decisions where intuition is activated are likely to be rather cumbersome. When considering these two implications then an expansion of the BI system to better support the project prioritization meetings appears to be a costly, but not necessarily viable, option. In large part this is due to the challenges related to the capturing and processing of the contextualized knowledge in which the intuitive judgements are grounded. Similarly, Arnott et al. (2017) recommend 
caution to be exerted when considering BI systems for strategic decisions, which mainly involve intuitive judgments, building in System 1.

In this study, it is difficult to assess the meetings effectiveness, or compare the outcome to different types of prioritization processes. The prioritization process is designed to elicit decisions about the proposed projects during the meetings from a group of managers who will be responsible for the implementation of the prioritised projects. The meetings increase information sharing and consensus building between the IT department groups and the top management, in contrast to a top down prioritization and resource allocation process, which would lack contextual information when translating organisational goals to project initiatives and about the actual workload of the proposed projects.

\section{Conclusion}

Our findings highlight the central role of intuitive judgements in organizational decision making. Our study contributes new knowledge regarding how intuitive judgements are communicated and shared in organizational decision making. We identified four techniques used by decision makers and described two conditions in which these techniques are used.

Our findings are based on an intensive case study, which allowed for a thorough investigation of the processes involved and offered analytical generalizability of the results. We believe that the findings of our thorough study can be observed in similar processes in other organizations. Further research should be conducted in different contexts (e.g., sectors, organization types, and cultures) to investigate the generalizability of the four techniques identified in our study.

\section{References}

Akinci C and Sadler-Smith E (2012) Intuition in management research: A historical review. International Journal of Management Reviews 14(1): 104-22.

Arnott, D., Lizama, F., \& Song, Y. (2017). Patterns of business intelligence systems use in organizations. Decision Support Systems 97: 58-68.

Barnard CI (1938) The Functions of the Executive. Cambridge, MA: Harvard University Press. 
Bazerman MH and Moore DA (2008) Judgment in Managerial Decision Making, 7th edn. New York, NY: Wiley.

Burke LA and Miller MK (1999) Taking the mystery out of intuitive decision making. Academy of Management Executive 13(4): 91-9.

Cannon-Bowers JA and Salas E (2001) Reflections on shared cognition. Journal of Organizational Behavior 22(2): 195-202.

Chase WG and Simon HA (1973) Perception in chess. Cognitive Psychology 4(1): 55-81.

Crandall B, Klein GA and Hoffman RR (2006) Working Minds: A Practitioner's Guide to Cognitive Task Analysis. Cambridge, MA: MIT Press.

Dane E and Pratt MG (2007) Exploring intuition and its role in managerial decision making. Academy of Management Review 32(1): 33-54.

Dane E and Pratt MG (2009). Conceptualizing and measuring intuition: A review of recent trends. In: Hodgkinson GP, Ford JK (eds.), International Review of Industrial and Organizational Psychology. Chichester: Wiley, 1-40.

Eisenhardt KM (1989) Building theories from case study research. Academy of Management Review 14(4): 532-50.

Epstein S (1994) Integration of the cognitive and the psychodynamic unconscious. American Psychologist 49(8): 709-24.

Evans JSBT (2003) In two minds: Dual-process accounts of reasoning. Trends in Cognitive Sciences 7(10): 454-59.

Evans JSBT (2010) Intuition and reasoning: A dual-process perspective. Psychological Inquiry 21(4): $313-26$.

Evans JSBT and Stanovich KE (2013) Dual-process theories of higher cognition: Advancing the debate. Perspectives on Psychological Science 8(3): 223-241.

Ghasemzadeh, F., \& Archer, N. P. (2000). Project portfolio selection through decision support. Decision Support Systems 29(1): 73-88. 
Handley SJ, Newstead SE and Trippas D. (2011) Logic, beliefs, and instruction: A test of the default interventionist account of belief bias. Journal of Experimental Psychology: Learning, Memory, and Cognition 37: 28-43.

Healey MP, Vuori T and Hodgkinson GP (2015) When teams agree while disagreeing: Reflexion and reflection in shared cognition. Academy of Management Review 40(3): 399-422.

Hodgkinson GP and Clarke I (2007) Conceptual note: Exploring the cognitive significance of organizational strategizing: A dual-process framework and research agenda. Human Relations 60(1): 243-55.

Hodgkinson GP and Healey MP (2011) Psychological foundations of dynamic capabilities: reflexion and reflection in strategic management. Strategic Management Journal 32: 1500-1516.

Hodgkinson GP and Healey MP (2014) Coming in from the cold: The psychological foundations of radical innovation revisited. Industrial Marketing Management 43: 1306-1313.

Hodgkinson GP, Langan-Fox J and Sadler-Smith E (2008) Intuition: A fundamental bridging construct in the behavioural sciences. British Journal of Psychology 99(1): 1-27.

Hodgkinson, GP and Sadler-Smith, E (2018) The dynamics of intuition and analysis in managerial and organizational decision making. Academy of Management Perspectives 32(4): 473-492.

Hodgkinson GP and Sadler-Smith E (2011) Investigating intuition: Beyond self-report. In: Sinclair M (ed) Handbook of Intuition Research. Cheltenham: Elgar, 52-67.

Hodgkinson GP, Sadler-Smith E, Burke LA, Claxton G and Sparrow PR (2009) Intuition in organizations: Implications for strategic management. Long Range Planning 42(3): 277-97.

Howell JM and Higgins CA (1990) Champions of technological innovation. Administrative Science Quarterly 35(2): 317-341.

Hough JR and Ogilvie DT (2005) An empirical test of cognitive style and strategic decision outcomes. Journal of Management Studies 42(2): 417-48.

Kahneman D (2003) Maps of bounded rationality: Psychology for behavioral economics. American Economic Review 93(5): 1449-75. 
Kahneman D and Klein G (2009) Conditions for intuitive expertise: A failure to disagree. American Psychologist 64(6): 515-26.

Kahneman D, Slovic P and Tversky A (1982) Judgment Under Uncertainty: Heuristics and Biases. New York, NY: Cambridge University Press.

Keltner D, Gruenfeld DH and Anderson C (2003) Power, approach, and inhibition. Psychological Review 110(2): $265-84$.

Kester, L, Griffin, A, Hultink, EJ and Lauche, K (2011). Exploring portfolio decision- making processes. Journal of Product Innovation Management 28(5): 641-661.

Khatri N and Ng HA (2000) The role of intuition in strategic decision making. Human Relations 53(1): 57-86.

Klein GA (1998) Sources of Power: How People Make Decisions. Cambridge, MA: MIT Press.

Klein GA (2003) Intuition at Work: Why Developing Your Gut Instincts Will Make You Better at what You Do. New York, NY: Currency/Doubleday.

Klein GA, Orasanu J, Calderwood R and Zsambok CE (1993) Decision Making in Action: Models and Methods. Norwood, NJ: Ablex.

Kowalczyk, M and Buxmann, P (2015). An ambidextrous perspective on business intelligence and analytics support in decision processes: Insights from a multiple case study. Decision Support Systems 80: $1-13$.

Kuo, F. Y. (1998). Managerial intuition and the development of executive support systems. Decision Support Systems 24(2): 89-103.

Lee T (1999) Using Qualitative Methods in Organizational Research. Thousand Oaks, CA: Sage.

Lewicki P, Hill T and Czyzewska M (1992) Nonconscious acquisition of information. American Psychologist 47(6): 796-801.

March JG (2006) Rationality, foolishness, and adaptive intelligence. Strategic Management Journal 27(3): 201-14. 
Markham SK (1998) A longitudinal examination of how champions influence others to support their projects. Journal of Product Innovation Management15(6): 490-504.

McAfee A, Brynjolfsson E, Davenport TH, Patil D and Barton D (2012) Big data. The management revolution. Harvard Business Review 90(10): 61-7.

Miles MB and Huberman AM (1994) Qualitative Data Analysis: A Methods Sourcebook, 2nd edn. Thousand Oaks, CA: SAGE Publications.

Miller CC and Ireland RD (2005) Intuition in strategic decision making: Friend or foe in the fast-paced 21st century? Academy of Management Executive 19(1): 19-30.

Payne JW, Bettman JR and Johnson EJ (1993) The adaptive decision maker. New York, NY: Cambridge University Press.

Padmanabhan, B., \& Tuzhilin, A. (1999). Unexpectedness as a measure of interestingness in knowledge discovery. Decision Support Systems 27(3): 303-318.

Ritchie WJ, Kolodinsky RW and Eastwood K (2007) Does executive intuition matter? An empirical analysis of its relationship with nonprofit organization financial performance. Nonprofit and Voluntary Sector Quarterly 36(1): 140-55.

Rosemann, M., \& Vessey, I. (2008). Toward improving the relevance of information systems research to practice: The role of applicability checks. MIS Quarterly 32(1): 1-22.

Sadler-Smith E and Shefy E (2004) The intuitive executive: Understanding and applying 'gut feel'in decision-making. Academy of Management Executive 18(4): 76-91.

Sadler-Smith E and Sparrow P (2008) Intuition in organizational decision making. In: Hodgkinson GP, Starbuck WH (eds) The Oxford Handbook of Organizational Decision Making. Norfolk: Oxford University Press, 305-24.

Sadler-Smith E (2016) 'What happens when you intuit?': Understanding human resource practitioners' subjective experience of intuition through a novel linguistic method. Human Relations 69(5): 10691093. 
Salas E, Rosen MA and DiazGranados D (2010) Expertise-based intuition and decision making in organizations. Journal of Management 36(4): 941-73.

Shariq S and Vendelø MT (2011) Contexts for tacit knowledge sharing. In: Schwartz DG, Te’eni D (eds) Encyclopedia of Knowledge Management. Hershey, PA: Information Science Reference, 121-30.

Shollo A, Constantiou I and Kreiner K (2015) The interplay between evidence and judgment in the IT project prioritization process. Journal of Strategic Information Systems 24(3): 171-188.

Simon HA (1955) A behavioral model of rational choice. Quarterly Journal of Economics 69(1): 99-118.

Simon HA (1987) Making management decisions: The role of intuition and emotion. Academy of Management Executive 1(1): 57-64.

Stanovich KE and West RF (2000) Individual differences in reasoning: Implications for the rationality debate? Behavioral and Brain Sciences 23(5): 645-65.

Strauss A and Corbin J (2008) Basics of Qualitative Research: Grounded Theory Procedures and Techniques, 3rd edn. Newbury Park, CA: Sage.

Tian, Q., Ma, J., Liang, J., Kwok, R.C.W., Liu, O. (2005). An organizational decision support system for effective R\&D project selection. Decision Support Systems, 39 (3), pp. 403-413.

Tingling P and Brydon M (2010) Is decision-based evidence making necessarily bad? Sloan Management Review 51(4): 71-6.

Trieu, V. H. (2017). Getting value from Business Intelligence systems: A review and research agenda. Decision Support Systems, 93: 111-124.

Woiceshyn J (2009) Lessons from "Good Minds": How CEOs use intuition, analysis and guiding principles to make strategic decisions. Long Range Planning 42(3): 298-319.

Yin RK (2003) Case Study Research: Design and Methods, 4th edn. Thousand Oaks, CA: Sage. 


\section{SHORT CVS}

Ioanna Constantiou is Professor of Information Systems Adoption at the Department of Digitalization in Copenhagen Business School and is employed part-time as a professor of Information Systems at the Department of Applied IT in University of Gothenburg in Sweden. Her current research focuses on the impact of sharing economy platforms in traditional industries as well as on digital transformation in the financial and maritime industries, with emphasis on data-driven decision making. Her research has been published in a number of academic outlets, including, the European Journal of Information Systems, the Journal of Information Technology, the Journal of Strategic Information Systems, the Communications of the ACM and the Electronic Markets. Her current research work focuses on the impact of sharing economy platforms in traditional industries as well as on digital transformation in the financial and maritime industries, with emphasis on data-driven decision making.

Arisa Shollo is Associate Professor at the Department of Digitalization in Copenhagen Business School. Her main research areas are organizational decision-making, management of IT and decision support. In particular, she is interested in analyzing companies' use of information with organizational decision-making as the main theoretical approach. Including, how organizations collect, analyze and use information in reach- ing organizational decisions. She has published her work in outlets such as Journal of Strategic Information Systems and Information Systems Journal and has presented her work at several international conferences, including Academy of Management, and the International Conference of Information Systems.

Morten Thanning Vendelø is Professor at the Department of Organization, Copenhagen Business School, and cofounder of the Copenhagen Center for Disaster Research (COPE). His research interests include crisis management, corporate reputation, crowd safety, organizational learning and adaptation, and sensemaking in organizations. His research is published in books and journals such as Creativity \& Innovation Management, Information \& Organization, International Journal of Disaster Risk Reduction, International Studies of Management and Organization, and Management Learning. 


\section{Highlights}

- Decision makers use their intuitive judgements when BI system's output is prescribed to be the main information source for decision making.

- Decision makers employ four techniques to communicate and share intuitive judgements during organizational decision making, which built on the BI output.

- The techniques of communicating intuitive judgment include framing calculations and connecting to the group context, while the techniques of sharing intuitive judgement include presenting intuitive judgements and appealing to an expert.

- The use of these techniques depends on the decision maker's familiarity with the group and the converge of perceptions about either a project or about specific issues in the group. 